\title{
Factors Related to Deaths Due to Suicides in Females Aged 12-24 Years
}

\author{
Kandagatla Krishnamurthy ${ }^{1}$, Shruthi Reddy Jillella ${ }^{2}$, Abhijith Subedhar ${ }^{3}$ \\ ${ }^{1}$ Tutor, Department of Forensic Medicine, Government Medical College, Nalgonda, Telangana, ${ }^{2}$ Senior Resident, \\ Department of Forensic Medicine, Gandhi Medical College, Secunderabad, Telangana, ${ }^{3}$ Professor, Department of \\ Forensic Medicine, Osmania Medical College, Hyderabad, Telangana
}

\begin{abstract}
Background: Suicide is a global health problem occurring in all parts of the world. It was the second leading cause of death among 15-29 year olds in 2016. Hence, an understanding of specific factors related to suicide would enable prevention strategies to be more sensitive.

Method: A cross sectional study was conducted in Department of Forensic Medicine, Gandhi Medical College, Secunderabad, which included all cases of suicidal deaths in females in the age group of 12-24 years in the period of January 2017 to November 2018.

Results: Majority cases belonged to the age group of 19-24 years (49\%). Many victims were from rural area $(60 \%)$, belonging to middle socioeconomic status $(57 \%)$ and unmarried $(80 \%)$. Majority of the victims were graduates i.e. $32 \%$ and $55 \%$ of them were students. The leading motive behind the suicides was emotional disturbances (21\%). Hanging is the most commonly adopted method to commit suicide i.e. $53 \%$ of deaths.

Conclusions: Most of the factors related to suicide are preventable. Suicides among the young can be prevented by starting student guidance clinics and should also incorporate woman specific strategies like providing education, economic security and empowerment of women.
\end{abstract}

Keywords: Suicides, females, adolescents, method of suicide, socio-economic factors.

\section{Introduction}

Suicide is awillful and voluntary act of a person who understands the physical nature of the act, and intends by it to accomplish the result of self-destruction. It is the deliberate termination of one's existence, while in the possession and enjoyment of his mental faculties. ${ }^{1}$ Suicidal behavior includes thinking about suicide (or Ideation), planning for suicide, attempting suicide and suicide itself. ${ }^{2}$

\section{Corresponding Author:}

\section{Dr. Shruthi Reddy Jillella}

Senior Resident, Department of Forensic Medicine, Gandhi Medical College, Secunderabad, Telangana e-mail: jillella.reddy9@gmail.com

Mobile Number: 9177694382
Suicide is a major public health problem all over the world. The world health organization (WHO) reports that every year more than $8,00,000$ people die from suicide and it was the second leading cause of death among 15-29 year-olds globally in $2016 .^{2}$ The results of a 2012 Lancet study on death by suicide in India exposed a shocking trend of suicide among adolescents, which showed that a large proportion of suicidal deaths occurred between the ages of 15 years and 29 years, especially in women. ${ }^{3}$ Adolescence is a stage of transition which needs mental capability, personality building and social adaptation. It has been observed that there is often a pressure to succeed over academics, relationship and self-identity during adolescence. Failure to overcome these challenges may lead to psychological distress and suicide. ${ }^{4} \mathrm{~A}$ greater understanding of region-specific factors related to suicide would enable prevention strategies to be more culturally sensitive. $^{5}$ 
The female suicidal behaviour in terms of total burden of morbidity and mortality combined is more in women than in men. ${ }^{6}$ Women's greater vulnerability may be due to gender related vulnerability to various psychopathology and psychosocial stressors. Current data fails to accurately depict the major female contribution to this public health problem. ${ }^{6}$ This study aims to identify the factors and precipitating causes that are responsible for suicidal deaths in females in 12-24 years age group.

\section{Materials and Method}

This was a cross sectional study done in the Department of Forensic Medicine Gandhi Medical College and Hospital, Secunderabad. The study included all cases of suicidal deaths in the age group of 12-24 years which were brought to mortuary for post mortem examination over a study period of 22 months (January 2017- November 2018). In cases where there was advanced decomposition and the cause of death could not be determined and in suspected poisoning cases where Chemical Analysis Report of Forensic Science Laboratory was negative, were excluded from the study. Socio-demographic variables and details about manner of death were obtained from reliable attendants of the deceased, hospital records, police records and inquest reports. Other details were obtained from the Postmortem examination and Forensic Science Laboratory and Histopathologyreports. The family members, relatives and friends were fully explained about the questionnaire and then verbal consent was taken from each individual before asking about the relevant details pertaining to the study and thus a total of 100 cases were analysed. Data was analysed using SPSS software and descriptive analysis was done. Data are presented in the form of text, tables and figures.

\section{Results}

The Total study group has been divided into 3 subgroups i.e., 12- 15 years, 16-18 years and 19-24 years. The highest number of cases were recorded in the age group of 19-24 group i.e. 49 cases (49\%), followed by 16-18 years group which recorded 38 Cases (38\%) and the least number of cases were seen in 12-15 age group with 13 Cases (13\%). In this study, the highest number of cases were recorded in the Hindus i.e. 94 cases (94\%) followed by, Muslims which recorded 6 Cases (6\%).

Table 1: Socio-economic factors related to suicide

\begin{tabular}{|c|c|c|c|}
\hline \multicolumn{2}{|l|}{ Factors } & \multirow{2}{*}{$\begin{array}{c}\text { Number of deaths } \\
40\end{array}$} & \multirow{2}{*}{$\begin{array}{c}\text { \% of deaths } \\
40 \\
\end{array}$} \\
\hline Cos & Urban & & \\
\hline Ueograpnical AIEd & Rural & 60 & 60 \\
\hline \multirow{4}{*}{ Socio-Economic Status } & Upper Class & 1 & 1 \\
\hline & Lower Class & 40 & 40 \\
\hline & Middle Class & 57 & 57 \\
\hline & Not Known & 2 & 2 \\
\hline \multirow{5}{*}{ Educational Status } & School & 19 & 19 \\
\hline & Intermediate $(10+2)$ & 22 & 22 \\
\hline & Graduate & 32 & 32 \\
\hline & Illiterate & 9 & 9 \\
\hline & Not Known & 18 & 18 \\
\hline \multirow{6}{*}{ Occupation } & Student & 55 & 55 \\
\hline & Employee & 13 & 13 \\
\hline & House Wife & 13 & 13 \\
\hline & Laborer & 9 & 9 \\
\hline & No Occupation & 7 & 7 \\
\hline & Not Known & 3 & 3 \\
\hline
\end{tabular}




\section{Marital Status}

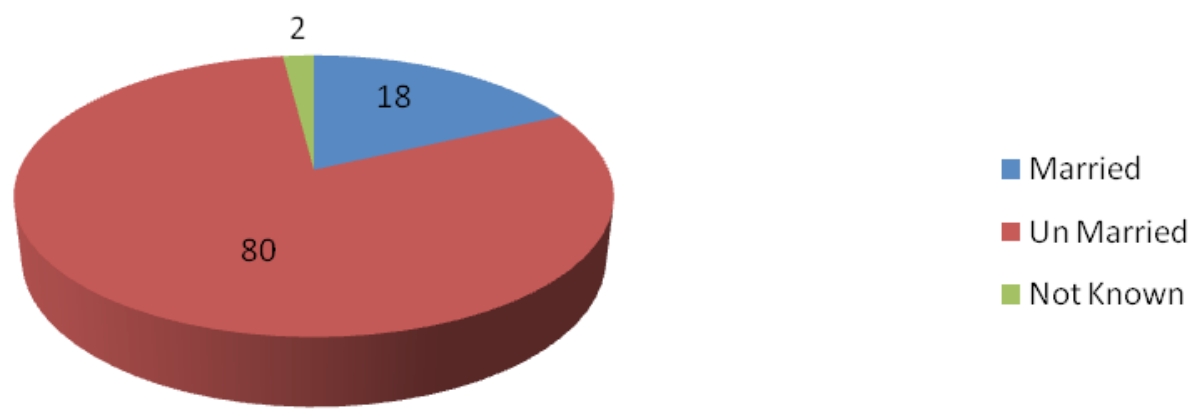

Fig 1: Marital status victims in deaths due to suicide in females aged 12-24 years

In this study group, $7(7 \%)$ cases of suicidal deaths occurred during menstruation. 1 (1\%) victim who committed suicide was pregnant. In 92 (92\%) of the cases, hormonal status of the victim was not known. According to the present study, in $24(24 \%)$ deaths, the motive behind the suicide was not known. In the remaining deaths, the leading motive behind the suicide was emotional disturbances amounting to 21 (21\%) deaths. The other motives in the decreasing order of frequency were illness and love related issues sharing $13(13 \%)$ each, failure in exams and economic problems sharing same percentage i.e. $9(9 \%)$ each, marriage related issues i.e. $6(6 \%)$ of deaths, harassment for dowry i.e. $4(4 \%)$ deaths and the least motive behind the suicide was death of a family member i.e. $1(1 \%)$ of deaths.

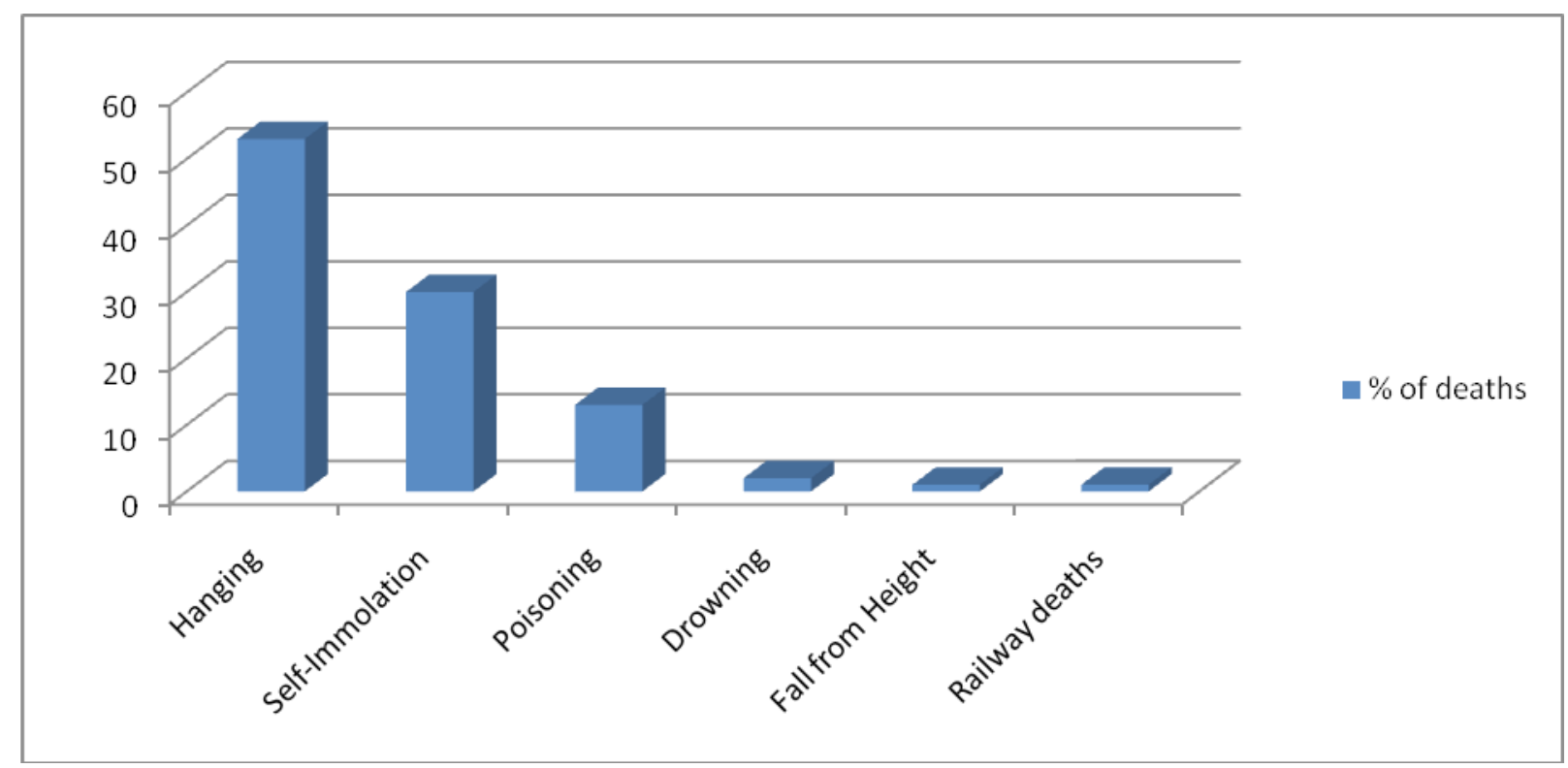

Fig 2: Cause of death due to suicide in females aged 12-24 years

\section{Discussion}

This study was conducted for over a period of 22 months in the mortuary of a Tertiary care centre i.e. Gandhi Medical College and Hospital, Secunderbad, Telangana, India.
According to the present study, the age group that constituted majority of deaths belonged to 19-24 years (49\%) subgroup, similar to study conducted by Khan et alin $2005 .^{7}$ This was followed by $16-18$ years age group which recorded $38 \%$ and the least number of cases 
were seen in 12-15 age group i.e. 13\%.Subjects from early study age groups (12-15 years) recorded deaths in lesser numbers. This may be due to unawareness of the suicide or submissiveness of the adolescent to their parents and society. Whereas it was more common in the late teenagers and young adults group (16-24 years), because of their short temperedness, social adjustment and hormonal surge issues, they became vulnerable for committing suicide. A study conducted by Aaron Ret al in southern India, concluded that youth is a period of increased risk of suicide and it is a leading cause of death among young people in India. ${ }^{8}$ As per the study, suicides accounted for $75 \%$ of all deaths in young women. ${ }^{8} \mathrm{~A}$ study by Omigbodun $\mathrm{OO}$ et al highlighted the role of media in providing information about various method of suicide among the youth. ${ }^{9}$ In the present study, the highest number of cases were recorded in the Hindus i.e. 94 cases $(94 \%)$ due to a higher percentage of Hindus in general population. Followed by, Muslims which recorded 6 Cases $(6 \%)$. The findings were similar to study by Kanchan T et al conductedin 2008 at Manipal, Karnataka. ${ }^{10}$

There is a major impact of various socio-economic factors in the risk of suicides. As per this study, it is observed that the victims predominantly belonged to the Rural group i.e. 60 cases (60\%), followed by Urban group which recorded 40 Cases (40\%), which is similar to study conducted by Sachinanda et alin 2003, where majority of the victims also belonged to the rural background. ${ }^{11}$ The higher incidence in rural areas is due to poverty, low education level, easy availability of poisonous substances like pesticides and lack of emergency care. In the current study, most of the deaths were noted in the Middle Class category accounting up to $57 \%$, followed by Lower class category (40\%) and least deaths were seen among the upper class category (1\%) but study by Sachinanda et al, showed majority of cases belonged to a lower socio-economic class. ${ }^{11}$ Majority of the deaths in middle and lower class population were due to lack of awareness and social stigma related with mental health disorders.

According to the present study, most deaths were noted in Graduates (32\%) which is followed by Intermediate students $(22 \%)$ and the least percentage of victims were seen in Illiterate category $(9 \%)$. The findings are comparable to study that was conducted by Chavan et al in 2008, where majority of the cases were matriculates. ${ }^{12}$ In the current study, majority of the deaths were noted among students (55\%) followed by Employees \& House wives, who were at the same rate i.e., $13 \%$. In this study, the students were most vulnerable group to commit suicide as they were under pressure to excel in studies. Sexual challenges, emotional issues, low self-esteem or insecurities, family or financial problems and even substance addiction may play an important part.

A study by Owens SA et al stated that some phases in menstrual cycle are linked to suicidal risk, predominantly among hormone-sensitive women, such as those with premenstrual dysphoric disorder or premenstrual exacerbation of a psychiatric disorder. ${ }^{13}$ In this study group, $7 \%$ of the suicides were committed during their menstruationphase. $1 \%$ suicidal deaths were seen in pregnant women. Majority of the deaths were seen among the unmarried women $(80 \%)$ when compared to married women (18\%), similar to studies by Chavan et al and Sarkar et al. ${ }^{12,14}$ Unmarried and single women are usually more prone to depression.

The most common motives behind suicide as per study conducted by Bastia B.K. et al were marriage related issues followed by failure in examinations. ${ }^{15}$ In the present study, in $24 \%$ of the death cases, the motive behind the suicide is not known. But, in the remaining deaths, the leading motive behind the suicide is emotional disturbances triggered by arguments at home, amounting to $21 \%$ deaths. The other motives were illness and love related issues, failure in exams, economic problems,marriage related issues, harassment for dowry and death of a close family member.

According to the current study, Hanging is the most commonly adopted method to commit suicide i.e. $53 \%$ of deaths. This is consistent with findings of other similar studies by Sachinanda et al, Chavan et al and Shaw et al,where hanging was the most common cause of suicidal death. ${ }^{11,12,16}$ The other means adopted to commit suicide in the decreasing order of percentage of deaths are Self Immolation which constituted 30\% of the deaths, $13 \%$ of the deaths were due to poisoning, $2 \%$ were due to drowning, and $1 \%$ each for fall from height and railway injuries.

\section{Conclusion}

Though suicide is a multi-factorial problem, most of these factors are either preventable or controllable. According to this study, students belonging to middle and lower socioeconomic status and residing in rural areas formed the most vulnerable group for suicides. 
Suicides among the young can be prevented by setting up of student guidance clinics not only to improve their psychological well-being, but also to enable them to explore their own potential to engage themselves in today's world with immense avenues. The educational system must be changed to promote holistic development of the child, rather than giving undue emphasis on academic achievements alone. Various mental health training programs must be conducted periodically for the medical officers and paramedical personnel of district hospitals and primary health care centers especially in rural areas, so that they can be trained in early detection and preliminary management of mental illnesses.

Suicide prevention programmes should also incorporate woman specific strategies which include providing education, economic security and empowerment of women. Proper assessment of the symptoms and prompt treatment for women suffering from physical illness and mood disorders should be done.

Ethical Clearance: Taken from Institutional Ethical Committee, Gandhi Medical College.

\section{Conflict of Interest: Nil}

\section{Source of Funding: Nil}

\section{References}

1. Ping NY, Panirselvam RR. The Endgame of Section 309?An Appeal for Decriminalisation of Suicide. Malaysian Journal Of Psychiatry. 2019; 28(1): 1-4.

2. World Health Organization 2014p. Preventing suicide: a global imperative. World Health Organization. Available at: https://apps.who.int/ iris/handle/10665/131056

3. Patel V, Ramasundarahettige C, Vijayakumar L, Thakur JS, et al. Suicide mortality in India: A nationally representative survey. Lancet 2012; 379(9834):2343-51. https://doi.org/10.1016/ S0140-6736(12)60606-0

4. Pisani AR, Schmeelk-Cone K, Gunzler D, Petrova $\mathrm{M}$, et al. Associations between suicidal high school students' help-seeking and their attitudes and perceptions of social environment. J Youth
Adolesc. 2012; 41(10):1312-24. doi: 10.1007/ s10964-012-9766-7.

5. Radhakrishnan R, Andrade C. Suicide: An Indian perspective. Indian J Psychiatry. 2012; 54(4): 30419. doi: 10.4103/0019-5545.104793

6. Vijayakumar L. Suicide in women. Indian J Psychiatry. 2015; 57(2): 233-8.

7. Khan FA, Anand B, Devi MG, Murthy KK. Psychological autopsy of suicide-a cross-sectional study. Indian J Psychiatry. 2005;47:73-8.

8. Aaron R, Joseph A, Abraham S, Muliyil J, et al. Suicides in young people in rural southern India. Lancet 2004; 363(9415):1117-8. doi: 10.1016/ S0140-6736(04)15896-0.

9. Omigbodun OO, Adejumo OA, Babalola OO. Suicide attempt by Hanging in preadolescent children: a case series. West Afr j Med. 2008;27(4):259-62.

10. Kanchan T, Menezes RG. Suicidal hanging in Manipal, South India - Victim profile and gender differences. Journal of Forensic and Legal Medicine. 2008 Nov; 8(15):493-6

11. Sachidananda M, Sahu M, Mohanty MK, Patnaik M. Suicide in India: A four year retrospective study. J. Forensic Leg Med. 2007; 14(4):185-9.

12. Chavan BS, Singh GP, Kaur J, Kochar R. Psychological autopsy of 101 suicide cases from northwest region of India. Indian J Psychiatry. 2008;50:34-8.

13. Owens SA, Eisenlohr-Moul T. Suicide Risk and the Menstrual Cycle: A Review of Candidate RDoC Mechanisms. Curr Psychiatry Rep. 2018 Oct; 20(11): 106.doi: 10.1007/s11920-018-0962-3.

14. Sarkar P, Sattar PA, Gode N, Basannar DR. Failed suicide and deliberate self-harm: A need for specific nomenclature. Indian J Psychiatry. 2006; 48(2):7883. doi: 10.4103/0019-5545.31594

15. Bastia BK, Kar N. A Psychological Autopsy Study of Suicidal Hanging from Cuttack, India: focus on stressful life situations. Arch Suicide Res.2009;13(1):100-4.

16. Shaw D, Fernandes JR, Rao C. Suicide in children and adolescents: A 10 year retrospective review. J Forensic Med Pathol. 2005;26(4):309-15. 